\title{
A ação pedagógica dos gestores principais de instituições francesas: oportunidades e tensões ${ }^{1}$
}

\author{
L'action pédagogique des chefs d'établissements français opportunités et \\ tensions \\ The pedagogical action of the main managers in french institutions: \\ opportunities and tensions \\ La acción pedagógica de los gestores principales de instituciones francesas: \\ oportunidades y tensiones \\ ANNE BARRÈRE
}

\begin{abstract}
Resumo: Este artigo tem como objetivo apresentar as representações e as convicções dos gestores principais de instituições francesas de ensino médio da região Norte da França e demarcar as principais tensões com as quais esses gestores se confrontam em suas novas missões pedagógicas. O estudo é resultado de pesquisa qualitativa sobre o trabalho dos gestores principais e a partir das experiências de colaboração da autora em vários mestrados profissionais destinados a estes profissionais. Conclui-se que na instituição escolar, apesar de progredir pouco a pouco, a autonomia dos docentes ainda é pouco discutida e, na França, ainda é forte o estabelecimento da burocracia nas relações entre os profissionais que nela atuam. Ainda existe a influência das configurações locais das instituições e diversos fatores envolvidos em favor das novas missões estabelecidas para os gestores principais, objeto de estudo deste artigo.
\end{abstract}

Palavras-chave: gestores principais; ação pedagógica; instituição escolar.

\begin{abstract}
This article aims to present the representations and convictions of the main managers of French high school institutions in the Northern region of France and to highlight the main tensions with which these managers confront each other in their new pedagogical missions. The study is the result of a qualitative research on the work of the main managers and from the experiences of the collaboration of the author in several professional masters for these professionals. It is concluded that in the school institution, although progressing little by little, the autonomy of the teachers is still little discussed and in France, the establishment of bureaucracy in the relations between the professionals who work in it is still strong. There is still the influence of the local configurations of the institutions and several factors involved in favor of the new missions established for the main managers, the object of study of this article.
\end{abstract}

Keywords: main gestors; pedagogical action; school institution. 
Resumen: Este artículo tiene como objetivo presentar las representaciones y las convicciones de los gestores principales de instituciones francesas de enseñanza secundaria de la región Norte de Francia y demarcar las principales tensiones con las cuales esos gestores se confrontan en sus nuevas misiones pedagógicas. El estudio es resultado de investigación cualitativa sobre el trabajo de los gestores principales y a partir de las experiencias de colaboración de la autora en varias maestrías profesionales destinadas a estos profesionales. Se concluye que en la institución escolar, aunque desarrolle poco a poco, la autonomía de los docentes todavía es poco discutida y, en Francia, aún es fuete el establecimiento de la burocracia en las relaciones entre los profesionales que en ella actúan. Aún existe la influencia de las configuraciones locales de las instituciones y diversos factores envueltos a favor de las nuevas misiones establecidas para los gestores principales, objeto de estudio de este artículo.

Palabras clave: gestores principales; acción pedagógica; institución escolar.

\section{INTRODUÇÃO}

Os gestores principais de instituição francesa do ensino secundárioº viram aumentar, desde a descentralização dos anos 1980, sua legitimidade pedagógica. Essa descentralização, apesar de bastante balizada uma vez que ela não questionou os programas e as seleções nacionais dos professores, deu, no entanto, margens de manobra aos estabelecimentos escolares, em particular no campo de dispositivos de ajuda e de apoio, mas também lhe solicitando a construção de um projeto, pertinente para cada região. Em consequência, ao lado das tarefas de organização e de administração tradicionais, que abarcavam aspectos pedagógicos, sem que eles fossem explicitados como tais, apareceram missões para estimular e animar as equipes docentes, devendo-se integrar a uma política geral da instituição levando em conta as especificidades e as evoluções do contexto escolar local. A pedagogia foi colocada então no centro da gestão escolar, não redutível à antiga direção das instituições, que supunha apenas gerir as instituições escolares. Trata-se doravante também de movimentá-las, de fazê-las evoluir.

No entanto, a implementação dessas novas missões não acontecem sem um certo número de tensões. É a partir de uma pesquisa qualitativa sobre o trabalho dos gestores principais de instituição, efetuada na região Norte da França no início dos anos 2000, e também a partir de nossas experiências de colaboração em vários mestrados profissionais destinados aos gestores principais

2 Nosso interesse recai sobre o principal ou os principaux de collège (gestores principais de instituição do Ensino Fundamental - segunda fase para alunos de 11 a 15 anos) e pelos proviseurs de lycée (gestores principais de instituição do Ensino Médio para alunos de 16 a 18 anos). As escolas francesas têm diretores, mas estes frequentemente continuam a dar aulas ao passo que os chefes de instituição estão desobrigados por completo da carga horária de sala de aula. Os diretores não avaliam os professores, no entanto, os chefes de instituição os avaliam. 
de instituição ${ }^{3}$, que tentaremos delimitar os contornos flutuantes de uma gestão pedagógica emergente, à procura de sua zona de expertise e de seus modos de intervenção. Partir da experiência cotidiana de trabalho das equipes diretivas, e em particular de suas relações com os professores, nos parece nesse nível frutuoso, pois acerca dessa matéria e para retomar as afirmações de Dejours (1998), às vezes é difícil impedir que o "discurso da organização recubra o real do trabalho". Ora, se o conjunto dos gestores principais de instituição adere majoritariamente à nova definição de suas missões, e ao projeto oficial de se tornar "o primeiro pedagogo da instituição”, tal adesão é concretamente colocada à prova no seu trabalho cotidiano.

Parece-nos importante, inicialmente, demarcar as representações e as convicções dos gestores principais de instituição neste domínio antes de examinar os dois pilares de sua ação, ou seja, a busca da eficiência e a da implicação dos professores na instituição; depois demarcar as tensões principais com as quais esses gestores se confrontam em suas novas missões pedagógicas.

\section{AS CONCEPÇÕES PEDAGÓGICAS DOS GESTORES PRINCIPAIS DE INSTITUIÇÃO}

Embora a especialidade pedagógica do gestor principal seja definida como transversal às aulas e às disciplinas, pode ser pertinente pesquisar a relação destes gestores com sua pedagogia, que aparece inicialmente ligada ao passado de docente, que a maioria deles experimentou ${ }^{4}$. Mas ela é definida também, no âmbito de suas novas funções, a partir de uma observação crítica dos professores.

\section{MOTIVAÇÕES CONTRASTADAS}

Quando os interrogamos sobre suas motivações nesta nova carreira, a totalidade dos gestores, anteriormente professores, diz ter ressentido ou experimentado a limitação do contexto da sala de aula. Tornar-se gestor principal de instituição é então, e primeiramente, ter uma visão mais ampla dos problemas e sobretudo ter uma esfera de ação mais ampla.

3 Desde 2008, colaboramos sucessivamente no Mestrado de Recursos Humanos nas instituições Educativas da Universidade de Lille 3, no Mestrado de M@dos da ESEN, no Mestrado POSEFI e na formação continuada de Lille 3, e enfim em Genebra e em Lausanne na Formação FORDIF destinada aos superiores educativos suíços.

4 Os professores constituem ainda aproximadamente três quartos do pessoal de direção recrutados na França, mesmo se sua origem tem a tendência de se diversificar, no tangente ao pessoal de direção e de orientação, mas também dentre os professores, vendo doravante mais professores do primário do ensino do ensino primário? O recrutamento se faz por concurso nacional. 
Alguns deles reconhecem de bom grado que essa mudança foi efetuada para romper com certa impressão de estagnação profissional, como esse principal: "Alguns deles atribuem uma grande importância à pedagogia, como os professores da Terceira República, são apaixonados pelo contato com os alunos, eu não estava me sentindo confortável, certo abatimento". São evocadas as impressões da rotina ou a visão de colegas mais velhos, já desiludidos. Esses gestores não têm motivação pedagógica determinada, é mais a questão de gerir outro nível organizacional, a instituição, que os impele a essa evolução de carreira.

Mas, para uma minoria significativa dos entrevistados, que teve experiência prática contínua e convincente das pedagogias inovadoras, trata-se, antes, de estender essas experiências a outro nível. São então as fortes convicções pedagógicas, até mesmo um certo militantismo, a causa da motivação para a mudança de ofício...

De fato, estamos diante de dois casos diferentes, que podem ter consequências no plano do posicionamento pedagógico. No primeiro, a dimensão de ruptura com o ofício docente é muito intensa, mas não é acompanhada por tomadas de decisões pedagógicas marcadas. Mas no segundo caso, a vontade de estender a docência por outros meios é acompanhada por uma visão mais clara e normativa da vantagem de pedagogias novas ou ativas, diferenciadas, às vezes sob a égide reivindicada de pedagogos tais como Freinet ou a Programação Neurolinguística (PNL). Veremos que esta situação poderá suscitar mais tensões na relação com os professores.

\section{CRÍTICAS ENGAJADAS DO JULGAMENTO DOCENTE}

Exceto essa minoria de inovadores pedagógicos experientes, que podem se pronunciar claramente em favor de determinados tipos de pedagogia, os gestores principais de instituição têm convicções comuns? Podemos falar em convicções subjacentes, amplamente convergentes em torno da denúncia do que poderíamos nomear "pedagogia negativa" de alguns professores. Desmoralizados, pessimistas, até mesmo fatalistas, os docentes não acreditariam suficientemente em sua própria capacidade de melhorar os resultados dos alunos, eles o desencorajariam exercendo mais sua função de árbitro do que a de treinador (MERLE, 1996; 1998). Essa pedagogia negativa admite principalmente duas explicações.

A primeira é a da avaliação docente, que os gestores principais são de fato levados a assumir nos conselhos de classe, ou nas entregas, às famílias, dos boletins escolares ao final de cada trimestre. Se a maioria deles temem essas reuniões, é precisamente porque, segundo eles, a negatividade docente pode ser expressa amplamente nelas. Os gestores principais encontram aí uma parte 
dos resultados de pesquisas sobre o efeito "Pigmaleão", que tende a mostrar a eficiência das representações positivas dos educadores sobre os aprendizados dos alunos, e inversamente o efeito contra produtivo das expectativas insuficientes (ROSENTHAL e JACOBSON, 1975; FELOUZIS, 1996). Como afirma um proviseur de ensino médio profissionalizante acerca dos alunos de sua instituição: "Howve alunos, durante alguns anos, que tiveram uma buzina nas orelhas e quatro anos de bużinas nas orelhas, 'você não vale nada, você não vale nada, você não vale nada', eles estão certos de que não valem nada".

Suspeita-se que os professores, como se fossem conservadores de um nível intangível e abstrato, não adaptam suficientemente suas avaliações aos esforços dos alunos, a seus projetos, às diferentes áreas de conhecimento nas quais eles se encontram.

Mas a avaliação é com frequência apenas a parte manifesta do iceberg da pedagogia negativa. Para um proviseur. "É um conjunto de coisas, uma avaliação muito severa, os alunos com dificuldade continuam com dificuldade, não se procura fazer com que eles progridam, continua-se com a aula expositiva como era antigamente". A pedagogia tradicional ou expositiva é menos criticada por si mesma do que por ela ser sinônimo de desmotivação ou de admissão de impotência pedagógica, e sua condenação permanece bastante geral e pouco justificada: "É preciso parar com os embates" disse esse principal, que porém dirá, uma pouco mais tarde, ser "alérgico a Meirieu"s.

A segunda é a da "incivilidade docente", mesmo a expressão podendo surpreender. Mas contrariamente ao que uma agenda mediática e política tende a construir da violência escolar, na qual as atitudes dos adultos são pouco discutidas e na qual eles são descritos como vítimas, os professores são aqui evocados como produtores, senão de violência, ao menos de palavras ou de gestos desrespeitosos, de acordo com a classificação do etnólogo Peter Woods que distingue entre professores produtores ou desencorajadores de desvios. Déficit e excesso de autoridade são, aliás, nesse assunto tidos como opostos, embora sejam sobretudo os professores que "humilham os alunos". Descritos como autoritários demais, esses professores são alvos das críticas mais mordazes da parte dos gestores principais. As entrevistas compreendem um impressionante repertório de ações docentes descritas como injustificáveis, trabalhos jogados ao chão, jogos de palavras irônicos com os nomes, inclusive de origem estrangeira, "coisas que não se dizem, dentre outras, não necessariamente racistas, mas percebidas como tais", "vexação oral, desleixado, retardado, horrores deste estilo...", "cérebro de passarinho, imbecil, gordo".

5 Philippe Meirieu é um pedagogo francês que participou ativamente do movimento de reflexão para a renovação do sistema escolar francês. 
O fato de o centro da injúria poder ser o julgamento escolar vem evidentemente complexificar o debate e o leva ao ponto precedente. Para a maioria dos chefes de instituição, a exemplo dessa principale, é evidente: "Apenas o fato de dižer a uma criança, 'você não serve para nada', é um insulto. É o negar naquilo que ele $\hat{e}$ '. Um principal descreve o comportamento de um dos professores em termos de "assédio pedagógico": "Alguém rigoroso ao extremo e quase obsessivo, quando ele implica com um aluno, ele não o larga mais ao ponto de ser uma obsessão, isto me parecia obsessão".

Assim, através desses dois pilares da observação e da crítica docente, vêse que os gestores de instituição são levados a conferir autonomia a uma esfera de expertise "relacional", centrada nas consequências pedagógicas do julgamento docente no sentido mais amplo. Mais que opções pedagógicas precisas, os gestores principais de instituição se pronunciam unanimemente por uma pedagogia da motivação, e põem em dúvida a capacidade de vários professores para conduzi-la adequadamente.

\section{PARA O TRABALHO EM EQUIPE}

O último ponto consensual entre os gestores principais de instituição é um apelo, muito compartilhado também, pelo trabalho em equipe repousando sobre a clássica crítica endereçada ao individualismo docente. Ele é, ao mesmo tempo, do ponto de vista deles, um sinal visível de implicação, mas também um meio de ação da instituição sobre a sala de aula, como explica um principal: "Há grupos que não pensaram sobre suas práticas pedagógicas; trata-se de fazer com que esses professores reflitam sobre métodos pedagógicos novos, em uma ou duas horas por mês (...) é necessário discutir sobre isso, se concertar com os professores, mas de qualquer modo é preciso, em dados momentos, reunir regularmente um conselho de ensino para ponderar a respeito dos métodos pedagógicos novos, mais adaptados, quando sentíssemos justamente essa necessidade etc".

Vê-se claramente que se instaura aí uma nova norma de avaliação ${ }^{6}$, até então muito pouco formalizada, em relação à implicação na instituição e não mais à atividade em sala. Os "bons professores" são, assim, aqueles que aceitaram de certa maneira o aumento de suas tarefas e cujo trabalho também é "visível" do ponto de vista da instituição. Eles estão engajados em projetos, assumem

6 Os gestores principais de instituição os avaliam anualmente atribuindo uma nota administrativa, que totaliza $40 \%$ da nota global, complementando os $60 \%$ das inspeções pedagógicas. Mas essa avaliação é bastante criticada como muito burocrática pelos gestores principais de instituição, dando-lhes meios de reconhecer sua implicação apenas pelo uso de uma ou duas fórmulas. 
as responsabilidades de coordenação, de montagem ou de dinamização dos dispositivos, ou, mais amplamente, são vistos como tendo uma atitude cooperativa ou positiva.

O número de professores que os gestores principais de instituição estimam "líderes" dos grupos varia, mas em torno de uma norma designada na maioria das entrevistas como um "terço expressivo" ou "uma pequena metade", o resto divide-se entre professores que trabalham apenas nas salas de aula, e "cumprem suas horas, mais nada" e uma minoria de professores refratários. Mas os professores dinâmicos nas instituições são também bons professores nas salas de aula? Para a maioria dos chefes de instituição, essa adequação não se constitui um problema. O entusiasmo manifesto na instituição é inevitavelmente produtivo em aulas. Outros são menos seguros de si, como é o caso relatado por esse principal, cuja esposa é uma excelente professora, no entanto, ela não é reconhecida em sua instituição, pois ela não fala muito de si, segundo ele. Ou o caso reportado por esse proviseur, que questiona certos projetos: "O que é um bom professor de inglês? Não é o professor que leva seus alunos a Londres por três dias... Conheço aqui pessoas de grande valor, que tem, às vezes, dificuldades com o trabalho em grupo, porque eles gostam de suas aulas, eles personalizaram suas aulas, seus alunos, seu material e... que são muito discretos. E essa discrição faz com que eles não saibam se vender".

Mas essas interrogações são minoritárias, provavelmente porque a definição ampliada do trabalho docente veio para facilitar as novas tarefas dos gestores principais de instituição na área pedagógica e para corresponder às necessidades da construção do espaço da instituição. Assim, a afirmação pedagógica dos gestores principais corresponde igualmente à da nova figura normativa do bom professor.

\section{NOVAS MARGENS DE MANOBRA}

Mas, passar das convicções à ação ou à motivação confronta os gestores principais de instituição à articulação problemática do espaço da instituição e do da sala de aula, o que explica uma certa prudência em geral, principalmente da parte dos principaux que estão em contato mais direto com as equipes, desejosos de evitar um conflito muito grande com os professores: trata-se principalmente de "não ser brusco", "não deixá-los desconfortáveis", "não agredi-los". Essa prudência, em ruptura aliás com um certo discurso institucional, pelo menos na França, que convida a assumir firmemente posições claras de gestão conflituosa, não impede os chefes de instituição de perceber uma forte tensão entre a temporalidade e as práticas de sala de aula, às quais eles só têm acesso indiretamente, e sua vontade fortemente expressa em "fazer mover as coisas", e as pessoas, em primeiro lugar, 
os docentes. Duas vias institucionais existem, apesar de tudo, para reduzir as tensões: a existência - bastante recente - de um certo número de dispositivos pedagógicos transversais que eles devem animar e coordenar; o direcionamento pelos resultados e a busca da eficiência.

\section{EM BUSCA DE UMA PEDAGOGIA PARA OS ESTABELECIMENTOS ESCOLARES}

Os gestores principais de instituição francesa são hoje encarregados de organizar um conjunto de dispositivos que podem materializar precisamente essa pedagogia da motivação e do encorajamento, e para os quais eles devem suscitar o engajamento dos professores. São vários dispositivos, mas todos têm em comum a constituição de espaços de intervenção pedagógica diferentes da sala de aula do dia a dia, necessitando de regulamentações de geometria variável. Se os gestores principais não questionam a autonomia dos professores em sua sala de aula, eles a circunscrevem, de fato, mais ou menos proximamente.

Pode-se citar primeiro a ajuda individualizada, a materialização por excelência da "pedagogia positiva" Trata-se aí, para os gestores principais de instituição, de um meio de articular preocupação com a heterogeneidade e com a cultura da avaliação. Diretamente articulada com a sala de aula já que, em geral, são os próprios professores que supostamente assumem a responsabilidade de responder às necessidades de reforço dos alunos, ela constitui um tipo de mudança organizacional da pedagogia diferenciada e é um verdadeiro consenso entre os gestores principais de instituição.

Os dispositivos interdisciplinares também fazem parte da pedagogia positiva ao proporem maneiras diferentes de trabalhar, por supostamente trazerem, além disso, motivação aos alunos e aos professores (KERLAN, 2003). Esses dispositivos, obrigatórios para o ensino fundamental e para o ensino médio, supõem que os professores de diferentes disciplinas orientam grupos de alunos em torno de projetos variados. Por exemplo, um principal conta como convenceu um professor de artes plásticas a participar de um projeto sobre árvore, em parceria com um museu vizinho, e em colaboração com um professor de francês. Muito negativo inicialmente, o professor teve de ceder, no final das contas, em vista de sua perseverança: "Fui um pouco insistente, sou tenaz, não sou violento, não sou brutal, mas sou tenaze, em geral, consigo ir até o fim no que faço”. Na instituição de ensino

\footnotetext{
7 A partir do retorno às aulas em 2000 nos collèges (escolas de ensino fundamental), foram implementadas horas de recuperação de conteúdo e uma ajuda individualizada na quinta série (ensino fundamental I). No lycée (ensino médio), a ajuda individual pode ser dispensada, desde 1984, sob forma de módulos em pequenos grupos de alunos nas matérias mais importantes.
} 
profissionalizante ${ }^{8}$ as opiniões são, às vezes, mais pessimistas. Esse proviseur lamenta o caráter obrigatório desses projetos dos quais alguns deles são muito superficiais, simples respostas a uma ordem hierárquica. São, por vezes, mais os professores de disciplina comum que se comprometem com esses projetos, de acordo com esse proviseur, em razão das necessidades de "remotivação" que existem nessas disciplinas, mas apenas algumas equipes, diz ele, trabalham corretamente: "Quando o professor acredita no projeto, funciona, quando não acredita, não funciona". Outros dispositivos surgiram em torno de missões como a integração dos alunos deficientes, ou ainda em torno de diferentes ações de educação artística e cultural, ou de prevenção da saúde.

O projeto da escola, obrigatório nas escolas francesas desde os anos 1990, é o terceiro aspecto desta pedagogia escolar. No entanto, as maneiras de considerá-lo são muito diferentes segundo as equipes diretivas, e pode-se mesmo dizer, já que aí também, trata-se "de acreditar nele", que eles acreditam de modo diferente. Para apenas sete dos quarenta chefes de instituição entrevistados, dada a insistência oficial sobre este tema, o projeto é global, e o centro da política da instituição escolar. Isto é mais frequente nas escolas de ensino médio. Nessa escola, um proviseur construiu um projeto tripartite: "instruir, educar, formar" para o qual ele lamenta encontrar pouco eco junto aos professores. Nas instituições profissionalizantes, essa proviseure, inovadora pedagógica experiente, também deseja vivamente uma elaboração global das ações: "Agora, todas as ações que são propostas ao longo dos anos: os projetos interdisciplinares, os módulos, as acõos culturais, educativas, todas elas respondem ao projeto da instituição, a uma prioridade ou outra, todas. E agora, há um sentimento de forte pertencimento ao projeto". Quando ela encontra os professores para reuniões individuais, ela os questiona igualmente sobre a maneira como eles se situam em relação ao projeto da instituição e como intervêm nele. Mas outros chefes querem distância desses projetos, um deles respondeu, provavelmente um pouco por provocação, que "o verdadeiro projeto é a felicidade na escola”. Na verdade, quando não há suficientemente acordo com os professores, o projeto pode se tornar um documento burocrático que, elaborado "na intimidade do escritório do chefe", os professores, no final das contas, não conhecem.

Enfim, um último espaço é aberto por dispositivos que concernem, principalmente, as escolas de ensino fundamental e, em primeiro lugar, as escolas difíceis, classificadas como educação prioritária ${ }^{9}$, por meio da prevenção

8 Na França existem escolas de ensino médio sem especialização e técnico de um lado, e profissionalizante de outro. Desde 2009, a duração do ensino médio nas escolas profissionalizantes foi alinhada ao ensino médio sem especialização e técnico, ou seja, passou a ser de três anos.

9 As políticas de educação prioritária existem desde 1981 e consistem em dotar os estabelecimentos que acolhem um público em dificuldade escolar e social de meios suplementares. Essas políticas, constantemente remanejadas e questionadas, entretanto, estendidas, são periodicamente contestadas em sua eficiência. 
ou da gestão da violência escolar e dos alunos mais difíceis (GLASMAN e OEUVRARD, 2003). Alguns dispositivos consistem em retirar alguns alunos das salas de aula - é o caso das salas de recuperação (MARTIN, BONNEUY, 2002); outros em abrir as escolas durante as férias, para atividades escolares e periescolar. Esses dispositivos são às vezes solicitados pelos professores, mas às vezes também julgados com reserva, como muito fora de suas competências, e consumindo muito tempo. Aí também, os gestores principais de instituição devem provar seu poder de persuasão e sua capacidade de mobilização, quando julgam esses dispositivos positivos. Em uma escola de ensino fundamental, o principal não hesitou em ignorar algumas demandas de ação feitas pela secretária de educação, como a de criar classe de recuperação, em vista das dificuldades pedagógicas de reintegração de alunos em aulas regulares e do alinhamento da atividade das aulas. Vê-se aí que a pedagogia da escola abre espaços de discussão, entre gestores principais de instituição e professores, mas também entre as próprias instituições e as demandas da secretária de educação e das inspeções.

No total, a presença de numerosos dispositivos, em particular em certos estabelecimentos de educação prioritária, favorece a constituição de um espaço pedagógico na escola. Com efeito, esses dispositivos tendo como característica propor organizações mais flexíveis, e não necessariamente organizadas em torno do encontro presencial do professor com sua turma, eles exigem uma regulamentação no nível da escola e oferecem um espaço de iniciativa à nova ação pedagógica dos gestores principais de instituição (BARRÈRE, 2013).

\section{EM BUSCA DA EFICIÊNCIA PEDAGÓGICA}

O segundo pilar da ação dos gestores prinipais de instituição vem, sem dúvida, da difusão crescente de uma cultura de avaliação da qual são mediadores privilegiados. A avaliação faz parte, daí em diante, das tarefas prescritas aos gestores de instituição e os impele a tornarem-se especialistas locais de sua escola. É, em grande parte, pelo "direcionamento dado pelos resultados", da produção de "diagnósticos compartilhados" que as equipes de direção supostamente exercem uma missão pedagógica sustentada por conclusões precisas. Numerosos indicadores estatísticos avaliam em vários aspectos (alunos, matérias principais, escolas) os resultados da ação educativa ${ }^{10}$. Além disso, desde 2002, um novo dispositivo prevê a realização, pelo próprio gestores principais de instituição da escola, a partir da sua posse, de uma auditoria interna, conduzindo à fixação dos

10 Desde 1994, as escolas de ensino médio têm à sua disposição indicadores para direcionamento.

654 - RBPAE - v. 33, n. 3, p. 645 - 664, set./dez. 2017 
objetivos por quatro anos, acordado após discussão com o inspetor escolar ${ }^{11}$. Enfim, a prática de auditorias se espalha pelo sistema educativo a partir do fim dos anos 1980, (DEMAILLY et alii, 1998), contribuindo amplamente para a difusão dos princípios e dos meios de avaliação. Assim, os gestores principais de instituição e as equipes diretivas só podem procurar interpretar e comentar os números presentes nas escolas, para tentar circunscrever margens de ação e construir estratégias pertinentes. Como se pode analisar essas interpretações e esses comentários?

Primeiro, esses "relatos sobre o resultado" contêm em germes o que se poderia chamar a certeza de um "efeito gestores principais de instituição", de uma ligação entre a ação do gestores principais de instituição e as performances escolares, pouco difundida aliás de maneira tão afirmativa, pelo menos na França, por resultados experts ${ }^{12}$. Isso é claramente salientado sobretudo pelas direções que viram o resultado da escola melhorar desde sua nomeação. Além da lista das qualidades pessoais do bom gestores principais de instituição, voluntarista, trabalhador, presente no cotidiano da escola, o argumento dos gestores principais de instituição "bem sucedidos" recaem mais sobre as decisões que eles tomaram e que, segundo eles, permitiram este progresso. A certeza de ter sido eficiente torna evidentemente confortável a formulação de hipóteses que podem parecer às vezes bem pontuais. Um proviseur pode, por exemplo, argumentar, a implementação da ajuda individualizada no primeiro ano de ensino médio para explicar um resultado de vinte pontos no $b a c^{13}$ do ano precedente, enquanto que a eficiência geral dessa ajuda está longe de ser verificada (DURU-BELLAT, 2002). Um outro proviseur atribuirá os bons resultados na área de mecânica da escola de ensino profissionalizante à criação de um centro de recursos e à melhor comunicação entre os professores de diferentes disciplinas.

Um segundo aspecto estrutural que aparece nesses relatos é a forte tendência a superestimar as margens de ação local. A tendência em pensar constantemente, como os economistas, destacando um "valor agregado" de um estabelecimento escolar, "todas as coisas sendo iguais", faz esquecerse frequentemente das mudanças relativas ao aspecto social do público para

11 Além disso, no âmbito de uma nova lei orgânica relativa às leis de finanças (LOLF), os estabelecimentos são incentivados, desde 2006, a construir um programa de ação flexível pelos objetivos, sem que esses dispositivos tenham até o momento, um caráter obrigatório.

12 No sentido estrito do termo, quer dizer de uma relação clara entre estilo de direção e performances (MEURET, 2003; GRISAY, 2006), um resultado que é muito difícil de ser admitido pelos interessados! Mas o termo "efeito chefe de instituição" é frequentemente empregado em um sentido mais amplo, e desse ponto de vista incontestável, uma vez que ele designa a importância do chefe de instituição na vida e no funcionamento local.

13 O baccalauréat (ou bac) é uma prova para a conclusão do nível secundário e para acesso ao nível superior. (NT) 
enfatizar os fatores internos de progresso (MEURET, 2000; COUSIN, 2000). Um proviseur, para se contrapor ao elitismo de sua escola, abre o estabelecimento para famílias mais populares, que ele traz da escola particular da vizinhança, questionase longamente, no entanto, sobre os fatores pedagógicos que desencadearam, na sequência, uma baixa no nível das performances, enquanto que essa baixa é provavelmente imputável, em grande parte, à modificação do público. Inversamente, são, às vezes, as direções de escola que lembram à sua hierarquia o impacto das mudanças sócio-demográficas no resultado. Assim, o principal, cujos resultados na prova nacional do ensino fundamental diminuíram vinte pontos em um ano, se defende na ocasião da auditoria mostrando como os melhores alunos "fugiram" para uma escola particular da vizinhança. São, portanto, estratégias pedagógicas das equipes que serão questionadas pelos inspetores, durante visitas que o principal qualificará de tensas. Enfim, a própria existência da cultura de avaliação, e a lógica do relato que a acompanha, vão juntas com a pesquisa de margens de ação, e logo da tendência à eliminação do campo de raciocínio daquilo sobre o que se pode apenas, por definições, agir muito dificilmente. Mas estas tarefas oriundas de expertise local dão evidentemente uma grande legitimidade aos gestores principais de instituição para agir.

Muitos gestores principais de instituição ponderam e falam hoje como especialistas de suas escolas, mais ou menos confiantes neles mesmos, da eficiência da sua própria política. As soluções institucionais mais correntes: trabalho em equipe, avaliações comuns, pedagogias diferenciadas, ajuda individualizada, até mesmo projeto de instituição, são creditadas geralmente à eficiência, ainda mais precisamente que elas são pouco ou mal implementadas no momento, por falta de mobilização suficiente. Elas dão então um conteúdo à fixação de estratégias prospectivas em uma visada de um progresso local.

\section{TRÊS TENSÕES ESTRUTURAIS}

As duas linhas de ação apresentadas no item anterior são mais ou menos implementadas dependendo das instituições, da coesão e da mobilização das equipes docentes, do voluntarismo das equipes diretivas. Mas além das diferenças contextuais, pode-se distinguir três grandes tensões estruturais.

\section{ATRASO DE TRABALHO NÃO FEITO}

A primeira entre elas, na matriz, acumula essas novas tarefas com as 
tarefas da administração ${ }^{14}$, que, segundo as declarações dos gestores principais de instituição, não foram aliviados, ao contrário, nesses últimos anos, e sobretudo da enorme quantidade de "trabalho relacional" no qual a presença do gestores principais de instituição e os encontros formais e informais que ele assume com uns e outros, são grandes consumidores de tempo e de energia. Os gestores principais de instituição reclamam de nunca poder "refletir", "distanciar-se", "construir uma visão das coisas" e vivem com a sensação de atraso constante de "trabalho político" não feito. Trancados nos escritórios por razões burocráticas inúteis, eles acreditam que poderiam estar "por boas causas prospectivas", como este proviseur expressa: "Organizar os simulados do baccalauréat", os conselhos de classe, é preciso ter feito o concurso de gestores principais de instituição para fazer isto? Isto nos ajudaria, nos parece, a nos dedicar às verdadeiras tarefas que são as da pedagogia, do avanço da instituição, o verdadeiro papel político". Determinar o caminho da instituição, desenhar os contornos do futuro, é assim que se define a essência do trabalho, às vezes confirmando a postura clássica do "decididor solitário". Para outros, trata-se mais de seguir as propostas docentes, mesmo ao preço de um tipo de autocensura e de frustração com a estrutura que impede a ação: “Tenho propostas, tenho ideias, mas isso não compete a mim..." De qualquer forma, a maior parte dos entrevistados citam uma impossibilidade de se distanciar da estrutura, o que os tornaria mais reflexivos na ação (MAROY, 2002). As tarefas da gestão pedagógica vem assim aumentar o conceito de "trabalho ideal" que pesa mentalmente, por sua falta de realização, no cotidiano da profissão (DUJARIER, 2006).

\section{ENVOLVIMENTO VERSUS EFICIÊNCIA? AS RELAÇÕES GESTORES PRINCIPAIS DE INSTITUIÇÃO - DOCENTES À PROVA}

A segunda tensão, decisiva, refere-se às consequências da emergência da gestão pedagógica na supervisão dos docentes. De fato, se, teoricamente, o direcionamento pelos resultados e a necessidade de mobilizar equipes para atuar na instituição são absolutamente compatíveis e constituem realmente os dois pilares solidários do discurso da mudança organizacional pelas direções de instituições, esta equação pode revelar-se problemática na prática.

\footnotetext{
14 A demanda de um secretário geral nas instituições, a qual poderiam delegar parte do trabalho administrativo, é uma demanda recorrente do sindicato principal dos chefes de instituição francesa, os SNPDEN, há muitos anos.

15 O baccalauréat é a prova que conclui o ensino secundário na França e dá acesso à universidade. Um simulado é um preparatório, um treinamento, antes da prova real.
} 
Decerto, como algumas pesquisas confirmam, não há necessariamente correlação entre eficiência pedagógica e mobilização na instituição (FELOUZIZ, PERROTON, 2007). Assim, face às constatações negativas reveladas por ocasião de uma avaliação (portanto, não nos esqueçamos, sujeita à revisão ou à discussão), ou face a uma discordância sobre a suposta eficiência de um projeto, a equipe diretiva pode assim tomar medidas que são suscetíveis de desanimar os docentes, inclusive de gerar conflitos inéditos. Ela pode, por exemplo, opor-se à continuação de projetos estimados importantes para as equipes, argumentando o impacto visivelmente fraco nos resultados.

É o caso das pesquisas a seguir, em duas escolas. Em uma delas, a ação "Livros em festa", realizada há muitos anos pelos docentes de francês, foi suprimida, pelo motivo de "menos-valia" recorrente do grupo nas avaliações. Seu diagnóstico é claro: "Os moleques que chegaram em 1997 chegaram com uma mais-valia em francês de $6 \%$ nas avaliações, no final do ano letivo no referente ao exame de conclusão do ensino fundamental, menos 17\%. Menos 17\% e a mais-valia que retiro - 23\%. Onde está a mais-valia com outra festa do livro? Em contrapartida, os mesmos alunos, em Matemática, em 1997, se saíram bem, é bastante paradoxal, tenho os números aqui, trabalhei no diagnóstico de minha escola no ano passado, retomei tudo, todos os números, os mesmos alunos em matemática, em 1997, na sexta série, eles tinham uma mais-valia de 23\%,foi totalmente o oposto". A conclusão o é igualmente: "Os professores que tinham uma mais-valia de 6\% descansaram durante 4 anos". Em outro colégio, aulas de acompanhamento no próprio estabelecimento que visa a se encarregar dos alunos retirados da aula, e que se tornara, segunda a principale, uma renda de horas extra para alguns docentes, sem um impacto real para os estudantes, é questionado. Os conflitos foram intensos, aliás a principale deixou a instituição pouco tempo depois, após a generalização de bloqueios relacionais. Certos gestores principais de instituição, uma minoria é verdade, podem igualmente ser levados a questionar uma abundância demasiada de projetos estritamente educativos, próximos da vida escolar, como os desafios desportivos, as ações humanitárias ou certas viagens. Juntamente com certos pesquisadores que advertem sobre a invasão do "ordinário da aula" pelo “extraordinário do projeto" (BOUVIER, ROCHEX, 1997), eles se questionam se não é melhor focar novamente nas dificuldades da aprendizagem e fustigar o que se poderia nomear de inflação do periférico.

De maneira um pouco paradoxal, outra tensão existe também quando certos gestores principais de instituição quase deploram os bons resultados de docentes que acreditam criticáveis em diversos aspectos - pedagogia bastante expositiva, falta de implicação na instituição -, mas face às quais eles não podem alegar desempenhos ruins para pregar uma mudança de práticas. Eles são assim privados da legitimidade que a "reatividade" dá a uma situação crítica, e até 
mesmo catastrófica. Os bons resultados consistem, dessa forma, em um freio à ação potencial da direção e à sua demanda de mobilização na instituição.

Enfim, como os docentes face aos alunos, no dilema do árbitro e do treinador (MERLE, 1998), certos gestores principais de instituição fazem questão de não "desanimar" os docentes merecedores - ou seja, comprometidos com a instituição ao passo que outros julgam prioritários confrontá-los com a verdade a verdade deles mais frequentemente - com respeito à eficiência e aos resultados. Mas seja qual for a solução escolhida, percebemos bem que ser "o primeiro pedagogo da instituição" supõe também uma capacidade de administrar um novo aspecto relacional face às equipes docentes que podem sentir sua autonomia pedagógica - e sua expertise individual - questionada ou ameaçada.

\section{A DIFÍCIL CONFLITUALIZAÇÃO DA PEDAGOGIA DE INSTITUIÇÃO}

Por fim, a gestão pedagógica em emergência dos gestores principais de instituição provavelmente sofre atualmente na França de um déficit de espaço institucional para debates. Decerto, as questões pedagógicas são a maior parte do tempo deslocadas para a questão do "estilo de autoridade" dos gestores principais de instituição, os mais intervencionistas dentre eles parecem a maior parte do tempo demasiadamente autoritários ou intrometidos nas práticas de aula. Conflitos surgem então, mas sem ter a ver com a pedagogia.

Contudo, o debate poderia ser estimulado, por não se tratar de uma questão fácil. $O$ apelo majoritário dos gestores principais de instituição pela pedagogia de projeto poderia ser questionado pelos docentes, no momento em que sua eficiência escolar é discutida, sobretudo em relação aos públicos desfavorecidos (TERAIL, 2002). Do mesmo modo, os diagnósticos efetuados, a partir da posse dos gestores principais de instituição, poderiam ser discutidos na instituição mas, na verdade, não o são apesar da demanda oficial de "diagnósticos compartilhados". Enfim, enquanto que uma equipe diretiva escolar em zona de educação prioritária é simultaneamente criticada por uma dispersão nos projetos e solicitada a elaborar uma "escola aberta" - um projeto a mais - uma reflexão global poderia ter sido feita sobre essa contradição. Porém, tais discussões continuam raras, ou muitas vezes confinadas nos gabinetes das equipes diretivas, dificultando a constituição de um espaço deliberativo.

Provavelmente, isso explica o motivo pelo qual a maior parte dos gestores principais de instituição questionados parecem em busca de uma hierarquia pedagógica intermediária na instituição e tentam constituí-la apoiando-se nos 
professores principais, nos coordenadores de disciplinas ${ }^{16}$ ou nos portadores de vários dispositivos. Mas mal ela aparece, e os gestores principais de instituição a consideram, em grande parte, nesse momento, mais como uma estrutura de apoio e de ajuda a seu próprio trabalho, e até mesmo como um modo de contornar os sindicatos. Um proviseur, mas é um caso extremo, fala inclusive de docentes que seriam "insubordinados". De modo geral, a constituição de um espaço de debate pedagógico dentro das instituições está ainda por acontecer. Pode-se entender nisso uma consequência da falta de implicação da maioria dos docentes na cultura da avaliação. Pode-se interpretar também como uma vontade das direções de manter o poder o que parece cada vez mais como um modo de legitimação da sua ação local e como uma busca de extensão de controle sobre o trabalho docente.

\section{CONCLUSÃO}

Se a instituição escolar continua a ser hoje na França o elo de uma "burocracia profissional" (MINTZBERG, 1984) na qual a autonomia dos docentes é pouco discutida, ele progride pouco a pouco apesar de tudo em favor dessas novas missões, exigências, mais ou menos impressionantes, dependendo das configurações locais das instituições.

O sucesso de alguns gestores principais de instituição em implicar as equipes docentes e em levá-las a considerar mais os resultados da sua ação pode ser interpretado, sem dúvida, à luz do esforço que realizam muitas vezes no trabalho relacional cotidiano de apoio à gestão de turma dos docentes. É um caso que se encontra frequentemente nas instituições difíceis, em particular na segunda fase do ensino fundamental. As equipes se inserem nos projetos na instituição, em contrapartida, a equipe diretiva os ajuda nos conflitos nas turmas difíceis. Essa troca implícita é ainda mais fácil, obviamente, quando os próprios docentes aderem aos novos dispositivos pedagógicos; é ainda mais vantajoso quando eles percebem que os alunos podem, potencialmente, provocar incidentes.

Em contrapartida, quando a tentativa de modernização pedagógica da instituição não é acompanhada de tal apoio, pode-se haver casos muito mais conflituosos, acentuado pelas eventuais certezas pedagógicas dos gestores principais de instituição e de eventuais "golpes” nos projetos em curso. Os gestores principais de instituição modernizadores são rapidamente julgados autoritários se

16 Os professores principais têm missão de coordenar todos os coordenadores de classe (uma dezena geralmente). Os coordenadores de disciplina, por sua vez, têm missão idêntica junto a seus colegas professores de mesma disciplina. 
persistem nos projetos em que não são apoiados realmente pelos docentes. Os conflitos podem então ficar maiores, e alimentar uma parte do mal-estar docente (BARRÈRE, 2017).

Obviamente, o cotidiano da maior parte das instituições escolares fica num meio-termo. A instituição emerge como espaço pedagógico mais ou menos unificado, e a preocupação da eficiência escolar é mais ou menos central dependendo do contexto. As instituições eficientes são muitas vezes dispensadas de novas formas de regulação pedagógicas, por equipes diretivas que são consideradas evidentemente mais legitimadas por déficit de eficiência.

A ação pedagógica dos gestores principais de instituição é assim amplamente devedora da maneira de conceber a supervisão do trabalho docente. Superiores de superiores, e no comando de equipes às vezes muito grandes, as equipes diretivas devem, ao mesmo tempo, convencer, se quiserem agir, assumindo cada vez mais um papel de expertise pedagógica e devem avaliar a dimensão da realidade vivida do trabalho docente. Esse novo espaço de ação será, provavelmente, no futuro, um projeto estimulante e comunitário para os atores e para a pesquisa, na medida em que ele envolve também uma maior articulação entre saberes de experiência e saberes de pesquisa necessária à construção de um espaço local de expertise, mas também um espaço de deliberação pedagógicos (CALLON, LASCOUMES, BARTHE, 2001).

\section{REFERÊNCIAS}

Barrère A., Au cœur des malaises enseignants, Paris, Armand Colin, 2017

Barrère A, «La montée des dispositifs : un nouvel âge de l'organisation scolaire », Carrefours de l'éducation, 2013, n³ 36, pp.95-117

Barrère A., Sociologie des chefs d'établissement, Paris, PUF, 2011 (2006).

Bouveau Patrick, Rochex Jean-Yves, 1997, Les ZEP, entre école et société, Paris, Hachette

Callon Michel, Lascoumes Pierre, Barthe Yannick, 2001, Agir dans un monde incertain, Paris, Seuil.

Dejours Christophe, 1998, Souffrance en France, Paris, Seuil.

Dujarier Marie-Anne, 2006, L’idéal au travail, Paris, P.U.F. 
Duru-Bellat Marie, 2002, Les inégalités sociales à l'école, Paris, P.U.F.

Felouzis Georges, 1996, L'efficacité des enseignants, Paris, P.U.F.

Felouzis Georges, Perroton Joëlle. Repenser les effets établissements : marchés scolaires et mobilisations. Revue française de pédagogie, 2007, n¹59, pp 103119

Glasman Dominique, Oeuvrard Françoise (dir.), 2003, La déscolarisation, Paris, La Dispute.

Kerlan Alain, 2003, « Parcours diversifiés : le collège unique en trompe-l'œil ? », in Jean-Louis Derouet (dir.), Le collège unique en question, Paris, P.U.F.

Maroy Christian (dir.), 2002, L'enseignement secondaire et ses enseignants, Bruxelles, De Boeck.

Martin Elisabeth, Bonnery Stéphane, 2002, Les classes relais, Paris, E.S.F.

Merle Pierre, 1996, L'évaluation des élèves, Paris, P.U.F.

Merle Pierre, 1998, Sociologie de l'évaluation scolaire, Paris, P.U.F.

Rosenthal Robert A, Jacobson Lenore, 1975, Pygmalion dans la classe, Tournai, Casterman.

Terrail J-P., 2002, De l’inégalité scolaire, Paris, La Dispute,

Woods Peter, 1990, Teachers Skills and Strategies, London-New YorkPhiladelphia, The Falmer Press.

ANNE BARRÈRE é professora na Université Paris Descartes, CERLIS, França. E-mail: anne.barrere@parisdescartes.fr 